\title{
C-reactive protein, immunoglobulin $G$ and complement co-localize in renal immune deposits of proliferative lupus nephritis
}

\author{
Christoffer Sjöwall, Anders I. Olin, Thomas Skogh, Jonas Wetterö, Matthias Morgelin, Ola \\ Nived, Gunnar Sturfelt and Anders A. Bengtsson
}

\section{Linköping University Post Print}

\section{Tweet}

N.B.: When citing this work, cite the original article.

Original Publication:

Christoffer Sjöwall, Anders I. Olin, Thomas Skogh, Jonas Wetterö, Matthias Morgelin, Ola Nived, Gunnar Sturfelt and Anders A. Bengtsson, C-reactive protein, immunoglobulin G and complement co-localize in renal immune deposits of proliferative lupus nephritis, 2013, Autoimmunity, (46), 3, 205-214.

http://dx.doi.org/10.3109/08916934.2013.764992

Copyright: Informa Healthcare

http://informahealthcare.com/

Postprint available at: Linköping University Electronic Press

http://urn.kb.se/resolve?urn=urn:nbn:se:liu:diva-96152 


\section{Full-length Research Paper}

Title: C-reactive protein, immunoglobulin G and complement co-localize in renal immune deposits of proliferative lupus nephritis

Running head: Tissue CRP, IgG and C1q co-localize in lupus nephritis

Authors: Christopher Sjöwall1\#*, Anders I. Olin ${ }^{2 *}$, Thomas Skogh ${ }^{1}$, Jonas Wetterö ${ }^{1}$, Matthias Mörgelin², Ola Nived ${ }^{3}$, Gunnar Sturfelt ${ }^{3}$, Anders A. Bengtsson ${ }^{3}$

* Dr. Sjöwall and Dr. Olin contributed equally to this study

1. Rheumatology/AIR, Department of Clinical and Experimental Medicine, Linköping University, Linköping, Sweden

2. Infection Medicine, Department of Clinical Sciences, Lund University, Lund, Sweden

3. Rheumatology, Department of Clinical Sciences, Lund University, Lund, Sweden

\section{\# Corresponding author:}

Rheumatology Unit, University Hospital, SE-581 85 Linköping, Sweden.

E-mail address: christopher.sjowall@liu.se

Telephone +46101032416

Fax: +46101031844

Keywords: C-reactive protein; C1q; autoantibody; immune complex; lupus nephritis; systemic lupus erythematosus; immunogold electron microscopy 
Abbreviations: (in order of appearance): CRP, C-reactive protein; C, complement protein; SLE, systemic lupus erythematosus; LN, lupus nephritis; ds, double-stranded; ANA, antinuclear antibodies; RES, reticuloendothelial system; ICs, immune complexes; SAP, serum amyloid P component; PTX3, pentraxin-3; PRMs, pattern recognition molecules; mCRP, monomeric C-reactive protein; SLEDAI, systemic lupus erythematosus disease activity index; ACR, American College of Rheumatology; SDI, Systemic Lupus International Collaborating Clinics/American College of Rheumatology damage index; Pi, pauci-immune; HSP, Henoch-Schönlein purpura; ISN/RPS, International Society of Nephrology/Renal Pathology Society; GFR, glomerular filtration rate; IF, immunofluorescence 


\section{ABSTRACT}

The pattern recognition molecules C-reactive protein (CRP) and C1q are of big interest in relation to the pathogenesis of systemic lupus erythematosus (SLE). Circulating autoantibodies against CRP and C1q are frequently found in SLE patients with active disease, particularly in lupus nephritis ( $\mathrm{LN})$, and rising levels reportedly relate to disease activity and outcome. If CRP-, or dsDNA- and/or C1q-containing immune complexes (ICs) are pathogenic in LN, glomerular IgG-deposits would be expected to colocalize with these antigens. In search for proof of this concept, renal biospsies from patients with active LN ( $n=5)$ were examined with high-resolution immunogold electron microscopy. Renal biopsies from patients with Henoch-Schönlein purpura, pauciimmune nephritis and renal cancer served as controls. IgG antibodies against CRP, C1q and nucleosomes were analyzed in pre-post flare sera. We could demonstrate that CRP, C1q, C3c and dsDNA were co-localized with IgG in electron dense deposits in the glomerular basement membrane/subendothelial space in all of the $5 \mathrm{LN}$ patients. Deposits of IgG, CRP, complement and dsDNA were 10-fold higher in LN compared to controls. All SLE patients had circulating anti-nucleosome antibodies; 4/5 had serum antibodies against CRP, dsDNA, and C1q at biopsy/flare. Despite a limited number of cases, the results support the notion of a pathogenic role not only for anti-dsDNA antibodies, but also for anti-CRP and anti-C1q in LN. The glomerular ICs may have been generated by deposition of circulating ICs or by in situ IC formation. 


\section{INTRODUCTION}

The clinical spectrum of systemic lupus erythematosus (SLE) is exceedingly heterogeneous, extending from mild cases limited to skin and joint manifestations to life-threatening conditions with renal impairment, severe cytopenias, central nervous system disease or thromboembolic events [1]. Circulating antinuclear antibodies (ANA) is a hallmark of SLE. Although changing levels of ANA directed against double-stranded (ds) DNA has been found useful to monitor lupus nephritis (LN) disease activity, antibodies to complement protein 1q (anti-C1q) have been reported to be somewhat more specifically associated with renal disease [2, 3]. Matrat et al. recommended that anti-dsDNA and anti-C1q antibodies should be used in combination to monitor LN disease activity [4]. In European SLE patients, renal involvement occurs over time in approximately one third of the cases, and LN remains a major cause of morbidity and mortality worldwide [5]. Prompt recognition and treatment of renal disease is important, as early response to therapy is highly correlated with a better outcome [6].

Although the mechanisms behind autoantibody formation in SLE are incompletely understood, a growing body of evidence suggests that apoptotic cells provide autoantigens serving as targets for the adaptive immune response [1]. This may be due to insufficient opsonization of apoptotic material by circulating scavenger molecules and thereby deficient receptor-mediated elimination of autoantigens via endocytic cells in the reticuloendothelial system (RES). The consequences of such deficient 'waste disposal' could be tissue deposition of autoantigens outside of the RES, abnormal exposure of autoantigens to the adaptive immune system leading to loss of tolerance with excessive formation of autoantibodies, and excessive formation of circulating and tissue-bound immune complexes (ICs) $[1,7,8]$. Thus, deposition of circulating ICs in tissues, such as the mesangial matrix of the kidney, or in situ formation of ICs due to binding of circulating autoantibodies to autoantigens, e.g. nucleosomes, planted in the glomeruli, can lead to classical complement activation, infiltration and Fc-gamma receptor mediated activation of phagocytic cells, and ultimately tissue damage and organ failure [8-10]. 
A number of promiscuous serum proteins involved in pathogen recognition and initiation of the immune responses, including C1q, C-reactive protein (CRP), serum amyloid P component (SAP), pentraxin-3 (PTX3), mannan-binding lectin, galectin-3 and $\beta 2$-glycoprotein I, can opsonize apoptotic debris and thereby facilitate their removal via the RES as described above $[11,12]$. These evolutionarily highly conserved pattern recognition molecules (PRMs) are pivotal components of the innate immune system and are of great interest in relation to the pathogenesis of lupus. The affinity of CRP and other pentraxins for cell nuclear antigens, their ability to activate the classical complement pathway and their affinity for Fc-receptors is thought provoking in relation to deficient 'waste disposal' and ANA formation in SLE, where a CRP response is often low or absent despite raised interleukin 6 in disease flares [11-13]. Homozygous deficiency of $\mathrm{C} 1 \mathrm{q}$ and $\mathrm{C} 1 \mathrm{r} / \mathrm{C} 1 \mathrm{~s}$ is associated with a very high risk to develop lupus ( $\geq 90 \%$ ), whereas heterozygous genetic deficiency of C1 components appears not to be associated with decreased serum levels of C1q or an increased risk of developing SLE [14]. Deficiency of PTX3 in autoimmune-prone mice was recently reported to promote lung disease rather than nephritis [15]. In a SAP knock-out model, SAP was shown to govern chromatin degradation and prevent formation of pathogenic autoantibodies [16]. Single nucleotide polymorphisms of the CRP gene have been found to be associated with low baseline levels of CRP, ANA production and increased susceptibility for SLE [17]. Furthermore, in 2 murine lupus models, subcutaneous CRP injections delayed the disease onset, reversed nephritis, and prolonged the survival of the animals $[18,19]$. Mannan-binding lectin, however, does not seem to be clearly associated with either susceptibility or disease severity in lupus [20]. Taken together, a large body of evidence strongly indicates a preventive and disease-modifying role for PRMs in autoimmunity, although the postulated protective role of CRP in lupus-prone mice has recently been questioned [21].

During the last decade, many groups have reported the presence of autoantibodies directed against PRMs and acute phase proteins in different conditions [22-26]. We have demonstrated associations between anti-CRP antibody levels and disease activity, histopathology as well as response to therapy in lupus patients [27, 28]. Hypothetically, anti-CRP antibodies could have nephritogenic properties by interfering with CRPmediated removal of ICs and/or nuclear autoantigens. However, since anti-CRP 
antibodies in SLE are not directed against the circulating pentameric form of CRP but rather to CRP monomers, a more likely pathogenic potential of circulating anti-CRP would be to target tissue-bound monomeric CRP (MCRP) [22]. Such mCRP has been detected in vessels, skeletal muscle, liver and in tissue of chronic renal disease, possibly with extrahepatically produced CRP [29-32]. The well-known fact that pentameric CRP activates the classical complement pathway, has also been reported to account for mCRP [33-35]. Two studies have indeed identified CRP deposited in renal specimens from LN patients by means of conventional immunofluorescence microscopy [36, 37]. In the study by Zuniga et al., co-localization of CRP and IgG was also reported [37].

The present study was undertaken to test the proof of concept regarding glomerular localization of IgG-ICs containing CRP, dsDNA and C1q in SLE patients with circulating autoantibodies against these antigens. 


\section{MATERIALS AND METHODS}

\section{Subjects}

5 patients at the Department of Rheumatology, Lund University Hospital, Sweden, fulfilling the 1982 American College of Rheumatology (ACR) classification criteria for SLE [38], were selected on the basis of: (i) an episode of active renal disease with proteinuria ( $>0.5$ gram of albumin per 24 hours), hematuria and/or cellular casts, plus (ii) histopathology compatible with diffuse proliferative LN including active lesions. Venous blood was drawn from each individual at the time-point for renal biopsy and sera were kept at $-70^{\circ} \mathrm{C}$ until analyzed. For most cases, sera were also available from time-points ahead of, and/or following, renal biopsy (not applicable for patient B). Disease activity was assessed by the SLE disease activity index-2K (SLEDAI) [39]. In addition, the index was also calculated using solely the renal items (R-SLEDAI). An improvement of at least 8 points in R-SLEDAI at the 6-month follow-up was required for the patient to be regarded as a renal responder. Disease severity/organ damage was estimated by the Systemic Lupus International Collaborating Clinics/ACR damage index (SDI) [40]. Clinical characteristics and laboratory findings of the patients are shown in Table I. The median number of fulfilled ACR criteria was 7 (range 5-7). The mean age at the time for biopsy was 39 years (range 24-69 years); 4 out of 5 patients were women. As disease controls, renal specimens and sera were obtained from (i) a 45 year-old woman with pauci-immune necrotizing crescentic glomerulonephritis (P-i nephritis) and (ii) a 4.5 year-old boy fulfilling the 1990 ACR classification criteria for HenochSchönlein purpura (HSP) [41]; he presented with hematuria, bowel angina, wall granulocytes on skin biopsy and renal histopathology compatible with IgA nephropathy. In addition, we included control specimen from (iii) healthy renal tissue originated from a patient undergoing nephrectomy due to renal cancer.

\section{Histopathology}

Renal biopsies were performed by percutaneous ultrasonography-guided puncture in accordance with a standard protocol. The specimens obtained were blinded and then classified by an experienced renal pathologist according to the 2003 International Society of Nephrology/Renal Pathology Society (ISN/RPS) guidelines for LN [42]. All biopsies were evaluated by both light microscopy and immunofluorescence. 


\section{Immunostaining and electron microscopy}

Renal LN biopsies were prepared for electron microscopy by fixation with $1.5 \%$ paraformaldehyde and $0.5 \%$ glutaraldehyde in $0.1 \mathrm{M}$ phosphate-buffered saline (PBS, $\mathrm{pH}$ 7.4) for $6 \mathrm{~h}$ followed by washing with PBS, dehydration in ethanol and embedding in Lowicryl ${ }^{\circledR}$ (Electron Microscopy Sciences, Hatfield, PA, USA). Ultramicrotome (LKB ultratome) sections were mounted on gold grids. For immunostaining, grids were floated on top of immune reagents displayed on sheets of Parafilm ${ }^{\circledR}$. Free aldehyde groups were blocked with $50 \mathrm{mM}$ glycine in PBS followed by blocking with $0.2 \%$ AURION BSA-c ${ }^{\mathrm{TM}}$ (AURION, Wageningen, the Netherlands) in PBS for 15 minutes. This blocking procedure was followed by overnight incubation with the primary antibodies in incubation buffer at $4^{\circ} \mathrm{C}$ (Table II). After extensive washing with incubation buffer, the grids were incubated with $200 \mu$ l gold-conjugated secondary antibodies (Table II) for $2 \mathrm{~h}$ at $4^{\circ} \mathrm{C}$. As a control for unspecific secondary staining, primary antibodies were omitted in a parallel experiment. Finally, sections were washed with water, stained with 2\% uranyl acetate and lead citrate, and examined with a Jeol JEM 1230 electron microscope operated at $80 \mathrm{kV}$ accelerating voltage. Images were acquired with a Gatan Multiscan 791 CCD camera (Gatan Inc., Warrendale, PA, USA).

We also analyzed previously collected renal biopsy specimens fixed with osmium tetroxide and embedded in an epoxy resin (EPON ${ }^{\mathrm{TM}}$, Momentive Speciality Chemicals, Houston, TX, USA). Sections were freshly prepared from these routinely processed blocks of tissue and thereafter subjected to an etching procedure to enhance the yield of immunolabeling. Briefly, after multiple rinses with water, sections were oxidized by treatment with saturated sodium metaperiodate $\left(\mathrm{NaIO}_{4}\right)$ for $30 \mathrm{~min}$ at room temperature. Sections were again washed with water and inactivated, blocked and incubated with antibodies as above. The different methods for preparation of samples for immunostaining provided no differences in tissue morphology of sections, and no differences in immunogenicity between experiments. All antibody combinations were performed for all LN and control specimens (Table II). For comparsions of immunostaining, gold-conjugate particle density was calculated and expressed as particles per square $\mu \mathrm{m}$. Co-localization was defined as molecular probes within $30 \mathrm{~nm}$ proximity, according to Philimonenko et al [43]. 
The 163p77 experimental antibody was chosen as a molecular tool for recognizing nucleosomes since it has previously been shown to co-localize with in vivo-bound autoantibody deposits (as in turn detected with gold-conjugated protein A) restricted to the electron dense deposits, and shown not to cross-react with regular glomerular basement membrane structures [44]. It also specifically binds purified nucleosomes in vitro. By this technique, co-localization studies could be performed simultaneously detecting trapped nucleosomes and their ligand without concomitant staining of the in vivo-deposited autoantibodies. We used 2 different primary antibodies for tissue CRP detection (Table II). The goat polyclonal anti-human CRP antibody was raised by immunization with a peptide mapping at the $\mathrm{C}$-terminus. This is positioned at the junctions of monomers within the pentamer, thus mainly hidden in the pentameric structure of CRP [45]. The second anti-CRP antibody, i.e. the murine IgG2a monoclonal anti-CRP antibody 5G4 has been frequently used to detect tissue-bound CRP, although the exact epitope-specificity has not been published $[46,47]$.

\section{Routine analyses}

Clinical laboratory tests included blood cell counts (hemoglobulin, leukocytes, lymphocytes, neutrophils and platelets), creatinine, CRP, complement components and IgG. CRP was measured by turbidimetry using high-sensitive technique. C1q was analyzed by electroimmunoassay, whereas C3, C4, C3dg and IgG were measured by nephelometry. Glomerular filtration rate (GFR) was estimated from creatinine levels.

\section{Autoantibodies}

ANA was analyzed by indirect immunofluorescence (IF) microscopy using multispot slides with fixed HEp-2 cells (ImmunoConcepts, Sacramento, CA, USA) as antigen substrate, and fluorescein-isothiocyanate (FITC) conjugated gamma-chain-specific antihuman IgG as detection antibody (DAKO, Glostrup, Denmark). The cut-off level for a positive ANA test was set at a titer of $1: 200$, corresponding to $>95^{\text {th }}$ percentile among 150 healthy female blood donors. Positive ANA tests were categorized regarding IF staining patterns and were endpoint titrated in 2-fold steps. Autoantibodies to extractable nuclear antigens (ENA) including SS-A, SS-B, Sm, snRNP, Scl-70 and Jo-1 were analyzed by double radial immunodiffusion (ImmunoConcepts). IgG-class anticardiolipin antibodies were assessed by enzyme-linked immunosorbent assay (ELISA; 
Orgentec, Mainz, Germany) with $40 \mathrm{GPL}$ as the cut-off limit for a positive test. IgG antiC1q (normal range $<16$ units/L) was measured by electroimmunoassay as previously described [48]. IgG anti-dsDNA antibodies were analyzed with Crithidia luciliae IF microscopy test using a cut-off titer of 1:10 (>99th percentile among 100 healthy blood donors).

\section{Anti-nucleosome and anti-CRP assays}

The sera were further analyzed with a commercial anti-nucleosome antibody assay (Quanta Lite Chromatin, Inova Diagnostics, San Diego, CA, USA) using histone-H1stripped calf-thymocyte chromatin as antigen. Reference serum was provided with the kit, and the procedure was performed according to instructions from the manufacturer (normal range $<20$ units). Patient sera were analyzed in duplicates.

IgG anti-CRP antibodies were analyzed by ELISA as previously described [28]. To avoid systematic errors, samples from all patients and controls were randomly mixed on the microtiter plates and analyzed simultaneously at one occasion. Anti-CRP antibody levels were expressed as the percentage of a positive reference sample from a SLE patient at flare representing 100 arbitrary units. The cut-off limit for positive result was calculated from the $95^{\text {th }}$ percentile obtained from healthy controls (normal range $<12$ units). The SLE reference sample was always included. To exclude the possibility of non-specific binding, each serum was also tested in the same way on uncoated plates.

\section{Statistics}

The GraphPad software (version 4.0; GraphPad Software Inc., San Diego, CA, USA) was used for preparing Figures 3-4, and for statistical evaluation. Correlation analyses were performed using Pearson's correlation coefficient. Two-tailed $\mathrm{p}<0.05$ was considered significant.

\section{Ethics}

Informed consent was obtained from all subjects. The research protocol was approved by the Regional Ethics Committee in Lund (H4 207/2005). 


\section{RESULTS}

IgG, C1q, C3c, CRP and dsDNA were detected in electron dense deposits of the renal subendothelial space and/or the glomerular basement membrane in biopsies from all of the 5 examined lupus patients (Figure $1 \mathrm{~A}-\mathrm{E}$ ). From the close-up panels, it is evident that IgG, C1q, C3c, CRP and dsDNA all had a co-localized distribution, defined as less than 30 $\mathrm{nm}$ proximity between probes [43]. In contrast, biopsy specimens from healthy renal tissue (Figure 2 A-D) and disease controls (HSP and P-i nephritis) only showed negligible staining without co-localization for the markers as compared with LN (Figure 3). Serum C1q levels analyzed at time-point of biopsy were inversely correlated with C1q gold-conjugate particle density in the corresponding LN specimens $(r=-0.90$, $p=0.015$ ), whereas serum CRP versus (v.s.) CRP gold-conjugate particle density did not reach statistical significance.

Serum autoantibody analyses (Figure 4 A-E) revealed that the anti-nucleosome antibody test was positive in all LN patients at the time-point of highest disease activity/nephritis (i.e. when renal biopsy was performed). Autoantibodies directed against $\mathrm{C} 1 \mathrm{q}$ and CRP, respectively, were detected in 4 of 5 individuals at the time-point of nephritis. Serum anti-CRP was never positive before or after the time-points of flare for any of the patients. Patient $\mathrm{C}$ showed raised anti-nucleosome antibody levels throughout the study period, whereas anti-C1q and anti-CRP were consistently negative. Raised levels of anti-C1q preceded nephritis in patient A, B and E, whereas elevated levels of anti-nucleosome antibodies preceded nephritis in patient $\mathrm{A}, \mathrm{C}$, and $\mathrm{E}$. Concerning the disease controls, the HSP serum did not have detectable anti-C1q, antiCRP or anti-nucleosome antibodies; the P-i nephritis serum did not have detectable antiC1q, whereas anti-CRP and anti-nucleosome antibodies were not analyzed.

The most prominent serum autoantibody patterns were seen in patients where the lupus debut included nephritis (patient D and E); evident elevations of all 3 autoantibodies were found here. Using accumulated pre-post nephritis data $(n=23)$, one could observe that anti-nucleosome and anti-C1q antibody serum levels were more interrelated $(r=0.42, p=0.046)$ than were the levels of anti-CRP v.s. anti-C1q or antinucleosome respectively (anti-CRP vs. anti-C1q, $r=0.23$; anti-CRP vs. anti-nucleosome, 
$r=0.12$ ). On the other hand, patient D had the highest levels of anti-CRP, yet with an ANA titer of 1:800, moderately elevated anti-nucleosome antibodies, barely positive anti-C1q, negative anti-dsDNA and absence of complement consumption.

The patients included in this study seemed to be representative of Swedish LN patients. 3 of 5 patients responded well to therapy with a reduction of R-SLEDAI at the 6-month control, and with no significant reduction of GFR at the last follow-up (Table I). Patients (A and D) who responded incompletely to the induction therapy were positive for all 3 autoantibodies at the time-point of biopsy. In fact, none of the patients were anticardiolipin antibody positive at the time-point of nephritis. However, 3 patients (A, B and D) had shown weakly to moderately positive reactions in samples preceding or after the present flares, but only one individual was diagnosed with antiphospholipid syndrome (A). 


\section{DISCUSSION}

Although the presence of autoantibodies directed against PRMs and acute phase proteins is nowadays well recognized, the pathogenic importance of this in lupus has not been proven [22-26]. Several studies have demonstrated that anti-C1q antibodies associate with the occurrence, and activity, of LN [2-4]. Our previous finding of correlations between elevated serum anti-CRP and LN with poor response to therapy urged us to further investigate the nephritogenic properties of these autoantibodies [28].

This immunogold electron microscopy study was done to test the proof of concept regarding a pathogenic role for IgG-class autoantibodies against CRP, C1q and dsDNA in LN, either by deposition of circulating ICs or in situ formation due to IgG-binding to antigens deposited in the tissue. All of the 5 SLE patients participating in the study had IgG co-localizing with CRP, C1q and dsDNA in the renal subendothelial space and glomerular basement membrane. In line with our findings, Zuniga et al. identified CRP co-localized with IgG in the mesangium of LN specimens using conventional immunofluorescence microscopy, whereas no staining for CRP was seen in IgA nephropathy or in normal renal biopsies [37]. However, Nakahara et al. reported CRP staining in glomeruli as well as in the mesangium of 4/6 LN patients, but also in other conditions with proliferative disease, including IgA nephropathy [36]. We find it plausible to interpret the tissue co-localization of IgG, C1q and CRP as ICs containing C1q-anti-C1q and CRP-anti-CRP antibodies of IgG class as well as dsDNA-anti-dsDNA and/or anti-nucleosome antibodies, respectively. However, other explanations are also possible. Obviously, rather than reflecting C1q/anti-C1q antibodies, classical complement activation may contribute to the co-localization of IgG, C1q and C3c. Similarly, the co-localization of IgG, CRP, and complement may be explained by secondary binding of CRP to C1q-containing ICs, and/or by primary CRP- (as well as ANA-) targeting of nuclear antigens deposited in the kidney and a subsequent recruitment of complement. A support for renal deposition of circulating CRP-containing ICs is the very interesting early finding by Maire et al. who identified mCRP molecules (together with C1qrs) as constituents of circulating ICs in a patient with SLE as well as in 
a patient with acute myeloic leukemia [49]. Indeed, also nucleosomes/chromatin is a well-recognized constituent in ICs from LN patients [50].

Results from the autoantibody analyses in the present study indicate that circulating and tissue-bound autoantibodies do not necessarily reflect the same situation. Whereas all LN specimens showed clear IgG-staining in co-localization with C1q as well as with CRP and dsDNA (nucleosomes), patient $\mathrm{C}$ was seronegative with regard to anti-C1q and antiCRP, although possibly due to consumption of circulating autoantibodies. Patient C responded well to induction therapy and reached renal remission without any organ damage at follow-up; this is in line with our previous findings [28]. Regarding accumulated data and the correlation between anti-C1q and anti-nucleosome antibodies, but not between these autoantibodies and anti-CRP, suggests that the latter may reflect an independent role in the pathogenesis of LN.

CRP binds extracellular glomerular matrix proteins such as laminin and fibronectin and could thereby constitute a target for anti-CRP antibodies [51, 52]. It has further been shown in vitro that CRP and anti-CRP antibodies assemble on the surfaces of cell remnants and induce a pro-inflammatory response when exposed to macrophages [53]. Considering that both anti-CRP detection antibodies used yielded very similar immunogold staining patterns, and that the caprine polyclonal antibody (Santa Cruz Biotechnology) mainly recognizes epitopes hidden in the pentameric structure of CRP, it is likely that tissue CRP detected herein is MCRP. This is consistent with previous findings and would enable anti-CRP autoantibodies to interfere with biofunctions of mCRP, since these autoantibodies bind mCRP rather than pentameric CRP [27, 29-31]. Furthermore, in SLE, anti-CRP antibody levels usually correlate poorly with circulating CRP levels $[22,27,28]$. Others have just shown that affinity-purified IgG anti-CRP from LN patients prevent binding of $\mathrm{mCRP}$ to $\mathrm{C} 1 \mathrm{q}$ and factor $\mathrm{H}$, and reduce mCRP-mediated clearance of late apoptotic cells [54]. These observations support that anti-CRP antibodies are of pathogenic importance in lupus. It is reasonable that native CRP under certain circumstances (such as inflammation with low $\mathrm{pH}$ ) may dissociate into subunits, deposit and expose neo-epitopes on tissue surfaces and consequently become target for autoantibodies. This scenario could be parallel to the development of anti-C1q antibodies in SLE [55]. 
Radanova et al. recently demonstrated that anti-C1q antibodies from LN patients may inhibit the interaction of C1q with immobilized CRP and IgG [56]. As regards classical complement activation by surface-bound CRP, we have previously shown that this can be prevented by sufficiently high levels of fluid-phase CRP, which consumes C1q [34]. However, tissue-bound mCRP may also modulate classical complement activation by recruiting C4-binding protein [35]. Taken together, this illustrates that tissue-bound and soluble CRP have a range of different roles regarding pro- and anti-inflammatory actions. Similar dual roles can be ascribed to classical complement activation by ICs; classical activation by tissue-bound IgG-containing ICs can mediate proinflammatory effects mainly due to recruitment of phagocytes. On the other hand, classical activation by circulating IgG-ICs increases their solubility, thereby preventing IC-precipitation and extrahepatic tissue deposition, at the same time as it promotes Fc- and complementreceptor mediated IC-elimination by Kupffer cells [57, 58].

To conclude, despite a limited number of cases studied, our results demonstrate colocalization of IgG, CRP, dsDNA and C1q in patients with proliferative LN. This supports our hypothesis of a pathogenic role not only for anti-dsDNA, but also for IgG anti-CRP and anti-C1q antibodies. Further studies on larger materials are warranted to shed more light on this matter. 


\section{ACKNOWLEDGEMENTS}

We thank Dr. Per Alm, Lund University Hospital, for classifying the renal biopsies according to ISN/RPS and Dr. Tony Marion, University of Tennessee, for providing us with monoclonal anti-dsDNA antibody 163p77. This study was financed by grants from the Swedish Research Council, Lund University Hospital, County Council of Östergötland, Swedish Society for Medical Research, the Swedish Rheumatism Association, the Swedish Society of Medicine, the foundation of National Board of Health and Welfare, the Crafoord foundation, the Professor Nanna Svartz foundation, King Gustaf V 80-year foundation, and the research foundations in memory of Alfred Österlund, Greta \& Johan Kock, Ingrid Asp, Magnus Bergvall, Clas Groschinsky, byggmästare Olle Engkvist and apotekare Hedberg.

Declaration of interest: The authors report no conflicts of interest. All authors are responsible for the content and writing of the paper. 


\section{REFERENCES}

1. Rahman A, Isenberg DA. Systemic lupus erythematosus. $N$ Engl J Med 2008;358:929-939.

2. Moroni G, Radice A, Giammarresi G, Quaglini S, Gallelli B, Leoni A, Vecchi ML, Messa P, Sinico RA. Are laboratory tests useful for monitoring the activity of lupus nephritis? A 6-year prospective study in a cohort of 228 patients with lupus nephritis. Ann Rheum Dis 2009;68:234-237.

3. Akhter E, Burlingame RW, Seaman AL, Magder L, Petri M. Anti-C1q antibodies have higher correlation with flares of lupus nephritis than other serum markers. Lupus 2011;20:1267-1274.

4. Matrat A, Veysseyre-Balter C, Trolliet P, Villar E, Dijoud F, Bienvenu J, Fabien N. Simultaneous detection of anti-C1q and anti-double stranded DNA autoantibodies in lupus nephritis: predictive value for renal flares. Lupus 2011;20:28-34.

5. Alonso MD, Llorca J, Martinez-Vazquez F, Miranda-Filloy JA, Diaz de Teran T, Dierssen T, Vazquez-Rodriguez TR, Gomez-Acebo I, Blanco R, Gonzalez-Gay MA. Systemic lupus erythematosus in northwestern Spain: a 20-year epidemiologic study. Medicine (Baltimore) 2011;90:350-358.

6. Bertsias GK, Salmon JE, Boumpas DT. Therapeutic opportunities in systemic lupus erythematosus: state of the art and prospects for the new decade. Ann Rheum Dis 2010;69:1603-1611.

7. Radic M, Herrmann M, van der Vlag J, Rekvig OP. Regulatory and pathogenetic mechanisms of autoantibodies in SLE. Autoimmunity 2011;44:349-356.

8. O’Flynn J, Flierman R, van der Pol P, Rops A, Satchell SC, Mathieson PW, van Kooten C, van der Vlag J, Berden JH, Daha MR. Nucleosomes and C1q bound to glomerular endothelial cells serve as targets for autoantibodies and determine complement activation. Mol Immunol 2011;49:75-83.

9. Mannik M, Merrill CE, Stamps LD, Wener MH. Multiple autoantibodies form the glomerular immune deposits in patients with systemic lupus erythematosus. $J$ Rheumatol 2003;30:1495-1504.

10. Ravetch J. In vivo veritas: the surprising roles of Fc receptors in immunity. Nat Immunol 2010;11:183-185.

11. Kruse K, Janko C, Urbonaviciute V, Mierke CT, Winkler TH, Voll RE, Schett G, Muñoz LE, Herrmann M. Inefficient clearance of dying cells in patients with SLE: anti-dsDNA autoantibodies, MFG-E8, HMGB-1 and other players. Apoptosis 2010;15:1098-1113. 
12. Tincani A, Spatola L, Prati E, Allegri F, Ferremi P, Cattaneo R, Meroni P, Balestrieri G. The anti-beta2-glycoprotein I activity in human anti-phospholipid syndrome sera is due to monoreactive low-affinity autoantibodies directed to epitopes located on native beta2-glycoprotein I and preserved during species' evolution. $J$ Immunol 1996;157:5732-5738.

13. Agrawal A, Singh PP, Bottazzi B, Garlanda C, Mantovani A. Pattern recognition by pentraxins. Adv Exp Med Biol 2009;653:98-116.

14. Truedsson L, Bengtsson AA, Sturfelt G. Complement deficiencies and systemic lupus erythematosus. Autoimmunity 2007;40:560-566.

15. Lech M, Römmele C, Kulkarni OP, Susanti HE, Migliorini A, Garlanda C, Mantovani A, Anders HJ. Lack of the long pentraxin PTX3 promotes autoimmune lung disease but not glomerulonephritis in murine systemic lupus erythematosus. PLoS One 2011;6:e20118.

16. Bickerstaff MC, Botto M, Hutchinson WL, Herbert J, Tennent GA, Bybee A, Mitchell DA, Cook HT, Butler PJG, Walport MJ, Pepys MB. Serum amyloid P component controls chromatin degradation and prevents antinuclear autoimmunity. Nat Med 1999;5:694-697.

17. Russell AI, Cunninghame Graham DS, Shepherd C, Roberton CA, Whittaker J, Meeks J, Powell RJ, Isenberg DA, Walport MJ, Vyse TJ. Polymorphism at the Creactive protein locus influences gene expression and predisposes to systemic lupus erythematosus. Hum Mol Genet 2004;13:137-147.

18. Rodriguez W, Mold C, Marnell LL, Hutt J, Silverman GJ, Tran D, Du Clos TW. Prevention and reversal of nephritis in MRL/lpr mice with a single injection of Creactive protein. Arthritis Rheum 2006;54:325-335.

19. Szalai AJ, Weaver CT, McCrory MA, van Ginkel FW, Reiman RM, Kearney JF, Marion TN, Volanakis JE. Delayed lupus onset in (NZB x NZW)F1 mice expressing a human C-reactive protein transgene. Arthritis Rheum 2003;48:1602-1611.

20. Jönsen A, Gullstrand B, Güner N, Bengtsson AA, Nived O, Truedsson L, Sturfelt G. Genetically determined mannan-binding lectin deficiency is of minor importance in determining susceptibility to severe infections and vascular organ damage in systemic lupus erythematosus. Lupus 2007;16:245-253.

21. Carlucci F, Cook HT, Garg A, Pepys MB, Botto M. Lack of effect of a single injection of human C-reactive protein on murine lupus or nephrotoxic nephritis. Arthritis Rheum 2010;62:245-249.

22. Sjöwall C, Wetterö J. Pathogenic implications for autoantibodies against Creactive protein and other acute phase proteins. Clin Chim Acta 2007;378:13-23.

23. O’Neill SG, Giles I, Lambrianides A, Manson J, D’Cruz D, Schrieber L, March LM, Latchman DS, Isenberg DA, Rahman A. Antibodies to apolipoprotein A-I, high- 
density lipoprotein, and C-reactive protein are associated with disease activity in patients with systemic lupus erythematosus. Arthritis Rheum 2010;62:845-854.

24. Shoenfeld Y, Szyper-Kravitz M, Witte T, Doria A, Tsutsumi A, Tatsuya A, Dayer JM, Roux-Lombard P, Fontao L, Kallenberg CG, Bijl M, Matthias T, Fraser A, ZandmanGoddard G, Blank M, Gilburd B, Meroni PL. Autoantibodies against protective molecules - C1q, C-reactive protein, serum amyloid P, mannose-binding lectin, and apolipoprotein A1: prevalence in systemic lupus erythematosus. Ann N Y Acad Sci 2007;1108:227-239.

25. Lakota K, Zigon P, Mrak-Poljsak K, Rozman B, Shoenfeld Y, Sodin-Semrl S. Antibodies against acute phase proteins and their functions in the pathogenesis of disease: a collective profile of 25 different antibodies. Autoimmun Rev 2011;10:779-789.

26. Lakota K, Thallinger GG, Cucnik S, Bozic B, Mrak-Poljsak, Ambrozic A, Rozman B, Blinc A, Tomsic M, Sodin-Semrl S. Could antibodies against serum amyloid A function as a physiological regulators in humans? Autoimmunity 2011;44:149158.

27. Sjöwall C, Bengtsson AA, Sturfelt G, Skogh T. Serum levels of autoantibodies against monomeric $\mathrm{C}$-reactive protein are correlated with disease activity in systemic lupus erythematosus. Arthritis Res Ther 2004;6:R87-94.

28. Sjöwall C, Zickert A, Skogh T, Wetterö J, Gunnarsson I. Serum levels of autoantibodies against $\mathrm{C}$-reactive protein correlate with renal disease activity and response to therapy in lupus nephritis. Arthritis Res Ther 2009;11:R188.

29. Diehl EE, Haines GK ${ }^{3 r d}$, Radosevich JA, Potempa LA. Immunohistochemical localization of modified C-reactive protein antigen in normal vascular tissue. $\mathrm{Am} \mathrm{J}$ Med Sci 2000;319:79-83.

30. Rees RF, Gewurz H, Siegel JN, Coon J, Potempa LA. Expression of a C-reactive protein neoantigen (neo-CRP) in inflamed rabbit liver and muscle. Clin Immunol Immunopathol 1988;48:95-107.

31. Schwedler SB, Guderian F, Dammrich J, Potempa LA, Wanner C. Tubular staining of modified C-reactive protein in diabetic chronic kidney disease. Nephrol Dial Transplant 2003;18:2300-2307.

32. Jabs WJ, Logering BA, Gerke P, Kreft B, Wolber EM, Klinger MH, Fricke L, Steinhoff J. The kidney as a second site of human C-reactive protein formation in vivo. Eur J Immunol 2003;33:152-161.

33. Bíró A, Rovó Z, Papp D, Cervenak L, Varga L, Füst G, Thielens NM, Arlaud GJ, Prohászka Z. Studies on the interactions between C-reactive protein and complement proteins. Immunology 2007;121:40-50. 
34. Sjöwall C, Wetterö J, Bengtsson T, Askendal A, Almroth G, Skogh T, Tengvall P. Solid-phase classical complement activation by C-reactive protein (CRP) is inhibited by fluid-phase CRP-C1q interaction. Biochem Biophys Res Commun 2007;352:251-258.

35. Mihlan M, Blom AM, Kupreishvili K, Lauer N, Stelzner K, Bergström F, Niessen HW, Zipfel PF. Monomeric C-reactive protein modulates classic complement activation on necrotic cells. FASEB J 2011;25:4198-4210.

36. Nakahara C, Kanemoto K, Saito N, Oyake Y, Kamoda T, Nagata M, Matsui A. Creactive protein frequently localizes in the kidney in glomerular diseases. Clin Nephrol 2001;55:365-370.

37. Zuniga R, Markowitz GS, Arkachaisri T, Imperatore EA, D’Agati VD, Salmon JE. Identification of IgG subclasses and C-reactive protein in lupus nephritis: the relationship between the composition of immune deposits and $\mathrm{Fc}$ gamma receptor type IIA alleles. Arthritis Rheum 2003;48:460-470.

38. Tan EM, Cohen AS, Fries JF, Masi AT, McShane DJ, Rothfield NF, Schaller JG, Talal N, Winchester RJ. The 1982 revised criteria for the classification of systemic lupus erythematosus. Arthritis Rheum 1982;25:1271-1277.

39. Gladman DD, Ibañez D, Urowitz M. Systemic lupus erythematosus disease activity index 2000. J Rheumatol 2002;29:288-291.

40. Gladman D, Ginzler E, Goldsmith C, Fortin P, Ginzler E, Gordon C, Hanly JG, Isenberg DA, Kalunian K, Nived O, Petri M, Sánchez-Guerrero J, Snaith M, Sturfelt G. The development and initial validation of the Systemic Lupus International Collaborating Clinics/American College of Rheumatology damage index for systemic lupus erythematosus. Arthritis Rheum 1996;39:363-369.

41. Mills JA, Michel BA, Bloch DA, Calabrese LH, Hunder GG, Arend WP, Edworthy SM, Fauci AS, Leavitt RY, Lie JT, Lightfoot RW Jr, Masi AT, McShane DJ, Stevens MB, Wallace SL, Zvaifler NJ. The American College of Rheumatology 1990 criteria for the classification of Henoch-Schönlein purpura. Arthritis Rheum 1990;33:11141121.

42. Weening JJ, D’Agati VD, Schwartz MM, Seshan SV, Alpers CE, Appel GB, Balow JE, Bruijn JA, Cook T, Ferrario F, Fogo AB, Ginzler EM, Hebert L, Hill G, Hill P, Jennette JC, Kong NC, Lesavre P, Lockshin M, Looi LM, Makino H, Moura LA, Nagata M; International Society of Nephrology Working Group on the Classification of Lupus Nephritis; Renal Pathology Society Working Group on the Classification of Lupus Nephritis. The classification of glomerulonephritis in systemic lupus erythematosus revisited. Kidney Int 2004;65:521-530.

43. Philimonenko AA, Janácek J, Hozák P. Statistical evaluation of co-localization patterns in immunogold labeling experiments. J Struct Biol 2000;132:201-210. 
44. Kalaaji M, Mortensen E, Jørgensen L, Olsen R, Rekvig OP. Nephritogenic lupus antibodies recognize glomerular basement membrane-associated chromatin fragments released from apoptotic intraglomerular cells. Am J Pathol 2006;168:1779-1792.

45. Shrive AK, Cheetham GM, Holden D, Myles DA, Turnell WG, Volanakis JE, Pepys MB, Bloomer AC, Greenhough TJ. Nat Struct Biol 1996;3:346-354.

46. Wolbink GJ, Brouwer MC, Buysmann S, ten Berge IJ, Hack CE. CRP-mediated activation of complement in vivo: assessment by measuring circulating complement-C-reactive protein complexes. J Immunol 1996;157:473-479.

47. Meuwissen M, van der Wal AC, Niessen HW, Koch KT, de Winter RJ, van der Loos CM, Rittersma SZ, Chamuleau SA, Tijssen JG, Becker AE, Piek JJ. Colocalisation of intraplaque $\mathrm{C}$-reactive protein, complement, oxidised low density lipoprotein, and macrophages in stable and unstable angina and acute myocardial infarction. $J$ Clin Pathol 2006;59:196-201.

48. Mårtensson U, Sjöholm AG, Sturfelt G, Truedsson L, Laurell AB. Western blot analysis of human IgG reactive with the collagenous portion of C1q: evidence of distinct binding specificities. Scand J Immunol 1992;35:735-744.

49. Maire MA, Barnet M, Carpentier N, Miescher PA, Lambert PH. Identification of components of IC purified from human sera: I. Immune complexes purified from sera of patients with SLE. Clin Exp Immunol 1983;51:215-224.

50. Fismen S, Hedberg A, Fenton KA, Jacobsen S, Krarup E, Kamper AL, Rekvig OP, Mortensen ES. Circulating chromatin-anti-chromatin antibody complexes bind with high affinity to dermo-epidermal structures in murine and human lupus nephritis. Lupus 2009;18:597-607.

51. Suresh MV, Singh SK, Agrawal A. Interaction of calcium-bound C-reactive protein with fibronectin is controlled by $\mathrm{pH}$ : in vivo implications. J Biol Chem 2004;279:52552-52557.

52. Hedberg A, Mortensen ES, Rekvig OP. Chromatin as a target antigen in human and murine lupus nephritis. Arthritis Res Ther 2011;13:214.

53. Janko C, Franz S, Muñoz LE, Siebig S, Winkler S, Schett G, Lauber K, Sheriff A, van der Vlag J, Herrmann M. CRP/anti-CRP antibodies assembly on the surfaces of cell remnants switches their phagocytic clearance toward inflammation. Front Immunol 2011;2:70.

54. Yang XW, Tan Y, Yu F, Zhao MH. Interference of antimodified C-reactive protein autoantibodies from lupus nephritis in the biofunctions of modified C-reactive protein. Hum Immunol 2012;73:156-163. 
55. Schaller M, Bigler C, Danner D, Ditzel HJ, Trendelenburg M. Autoantibodies against $\mathrm{C} 1 \mathrm{q}$ in systemic lupus erythematosus are antigen-driven. J Immunol 2009;183:8225-8231.

56. Radanova M, Vasilev V, Deliyska B, Kishore U, Ikonomov V, Ivanova D. Anti-C1q autoantibodies specific against the globular domain of the $\mathrm{C} 1 \mathrm{qB}$-chain from patient with lupus nephritis inhibit C1q binding to IgG and CRP. Immunobiology 2012;217:684-691.

57. Skogh T, Stendahl 0. Complement-mediated delay in immune complex clearance from the blood owing to reduced deposition outside the reticuloendothelial system. Immunology 1983;49:53-59.

58. Skogh T, Blomhoff R, Eskild W, Berg T. Hepatic uptake of circulating IgG immune complexes. Immunology 1985;55:585-594. 


\section{FIGURE LEGENDS}
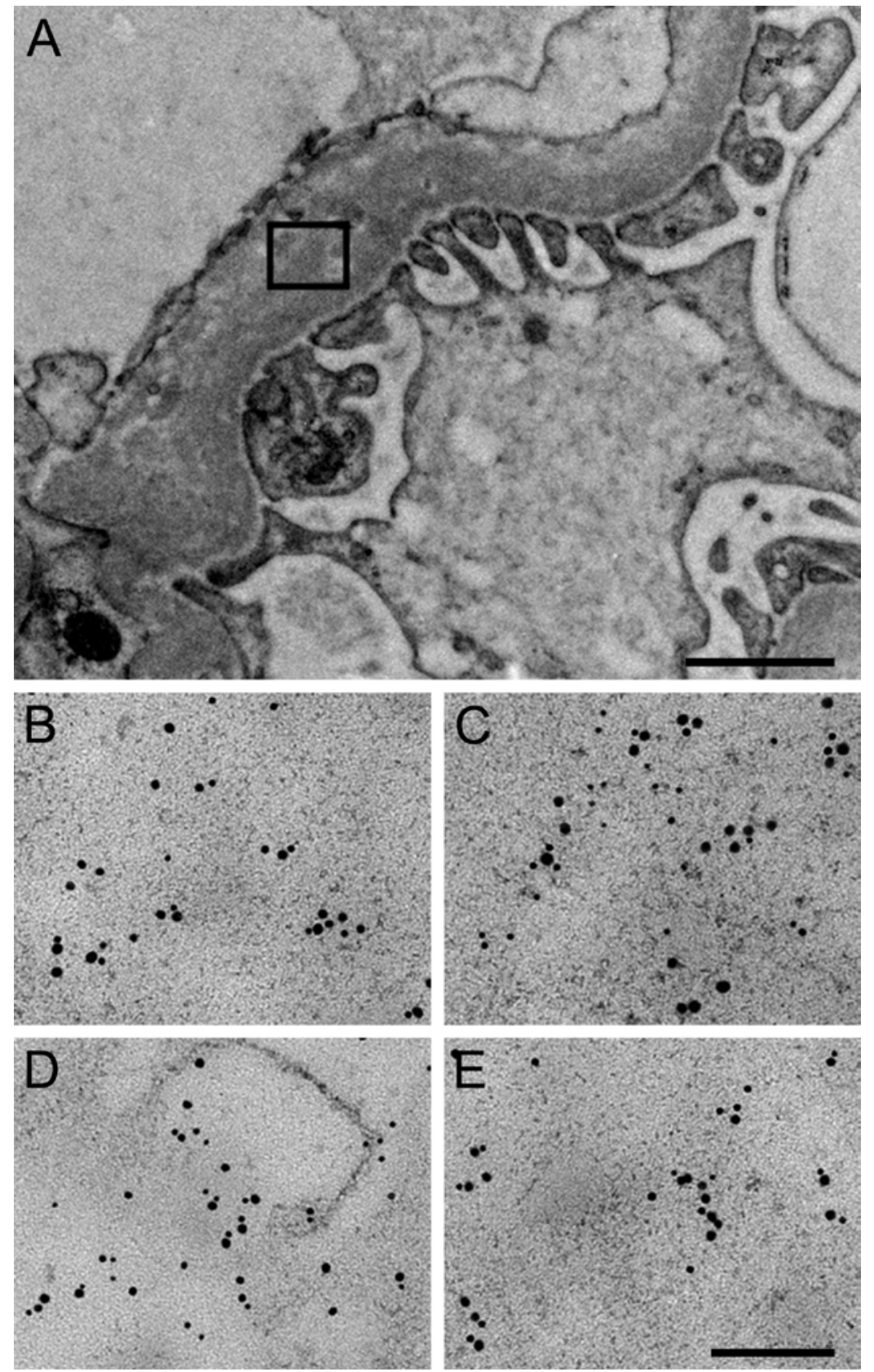

Figure 1: Representative localization images with immunogold electron microscopy of glomerular basement membrane from lupus nephritis renal biopsies. An overview of glomerular basement membrane carrying electron dense deposits is shown in panel A. From magnifications of typical electron dense deposit sections (boxed area of A) colocalization is indicated by the proximity $(<30 \mathrm{~nm})$ of the 2 different sized goldconjugates [43]. B, CRP (5 nm) and C1q (10 nm). C, dsDNA/nucleosome (5 nm) and CRP $(20 \mathrm{~nm}) . \mathbf{D}, \mathrm{dsDNA} /$ nucleosome $(5 \mathrm{~nm})$ and C3c $(10 \mathrm{~nm})$. E, CRP (5 nm) and IgG $(12 \mathrm{~nm})$. Scale bar: A, $1 \mu \mathrm{m}$; B-E, $100 \mathrm{~nm}$. 


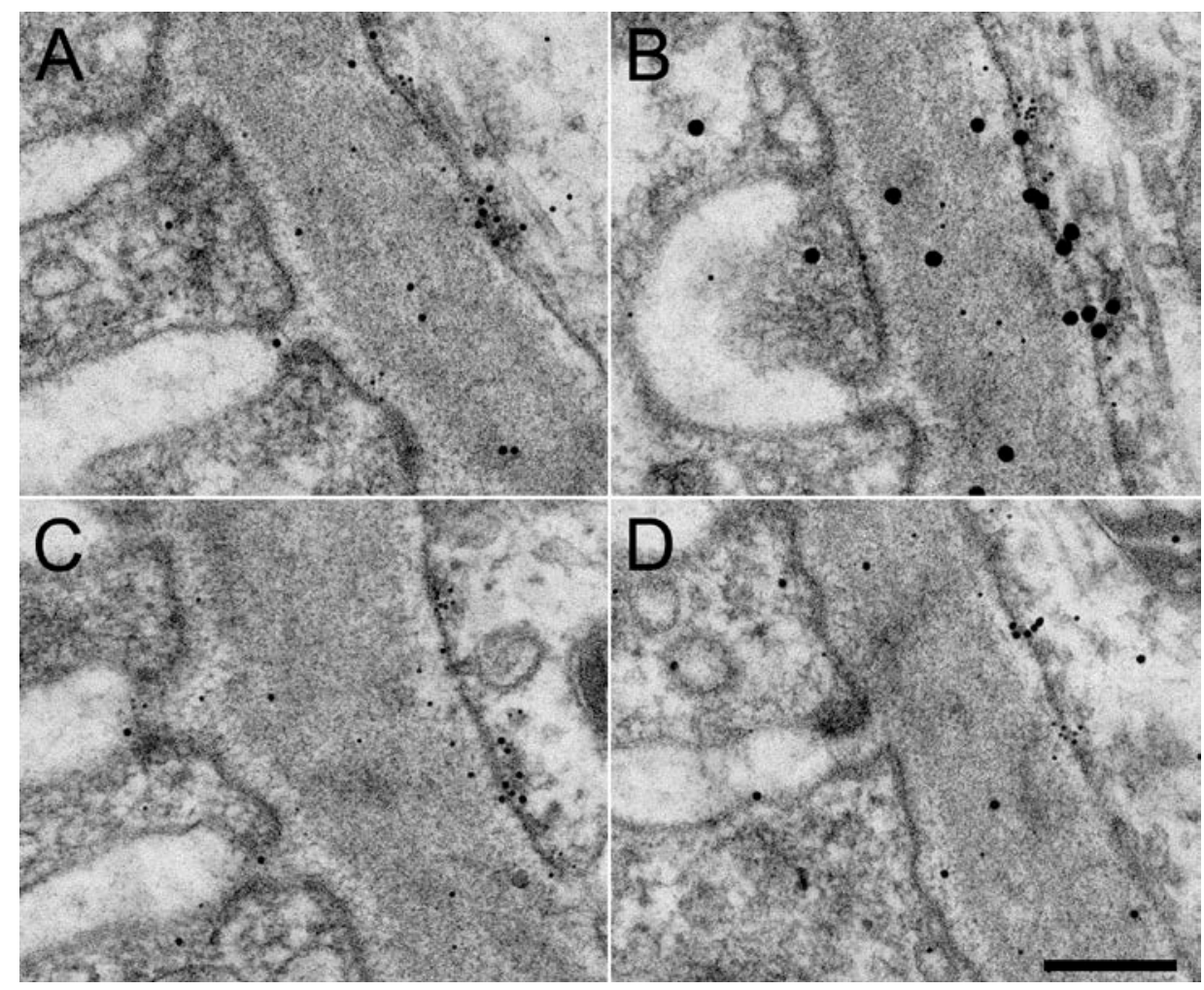

Figure 2: Immunogold electron microscopy of glomerular basement membrane performed on healthy renal tissue (A-D). Panel A, shows combination of CRP (5 nm) and C1q (10 nm); B, dsDNA/nucleosome (5 nm) and CRP (20 nm); C, dsDNA/nucleosome (5 $\mathrm{nm})$ and C3c (10 nm); and D, CRP (5 nm) and IgG (12 nm). No apparent co-localization was found. Scale bar: A-D: $200 \mathrm{~nm}$. 


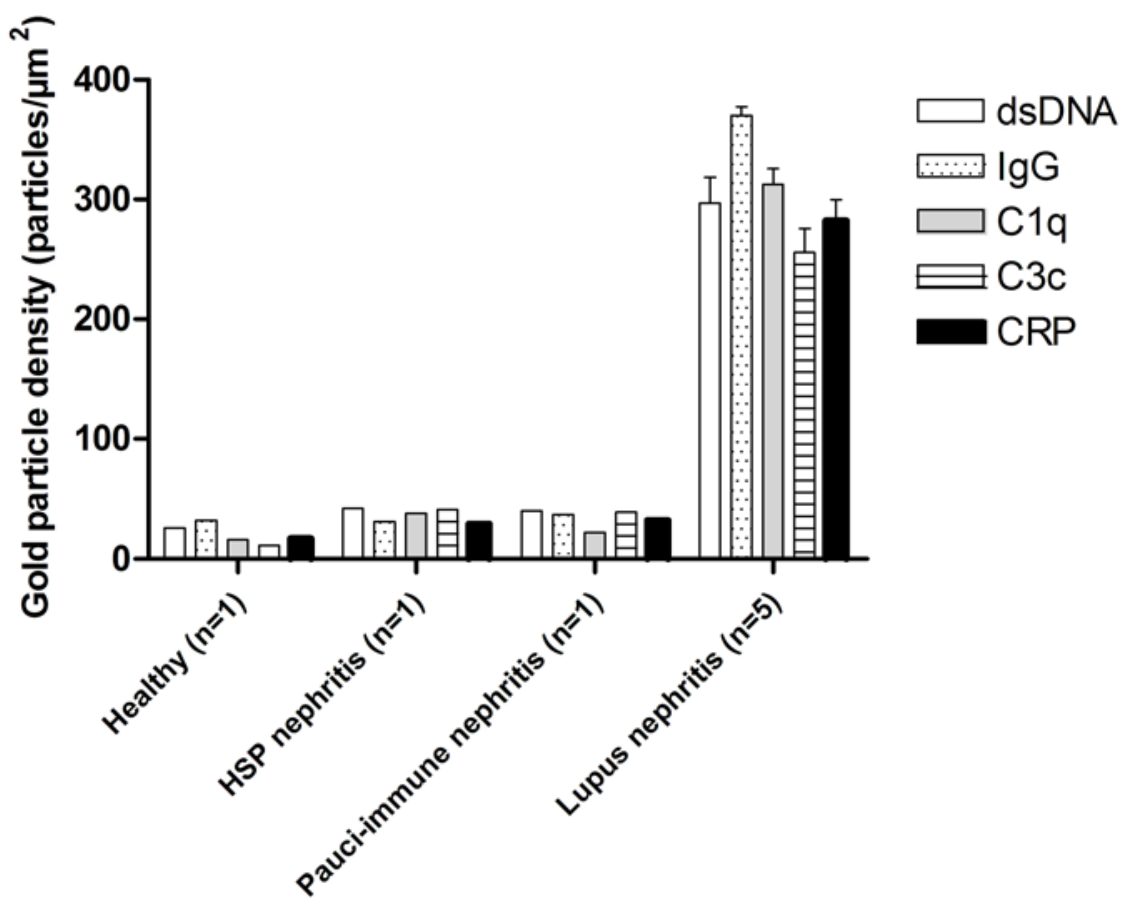

Figure 3: Analysis of the immunogold electron microscopy gold-conjugate particle density. Data represent means with standard deviations shown for lupus nephritis patients. 
Figure 4

A

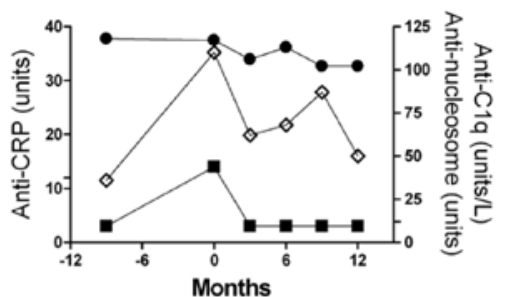

C

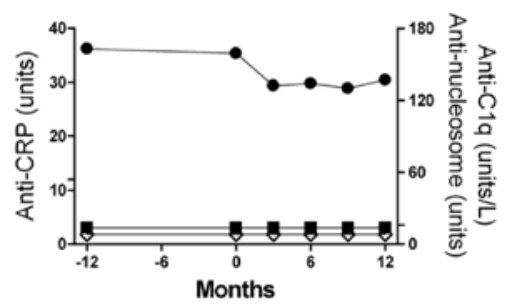

B

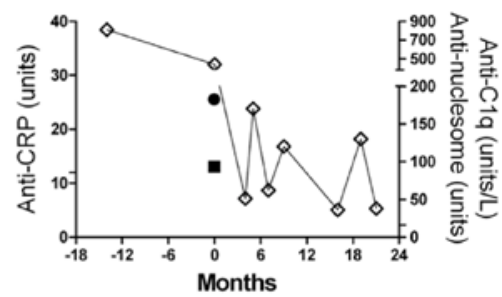

D

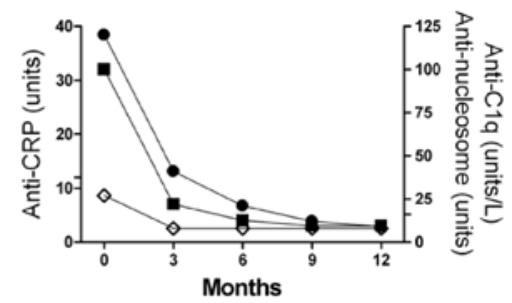

- Anti-CRP

$\rightarrow$ Anti-C1q

- Anti-nucleosome

Figure 4: Autoantibodies against CRP, C1q and nucleosomes demonstrated over time in the 5 LN patients. Month '0' represents the time-point of renal biopsy and highest renal disease activity. Pre-post flare samples for anti-CRP and anti-nucleosome antibody analysis were not available in patient B. Cut-off limits for anti-CRP was 12 units, antiC1q 16 units/L and anti-nucleosome antibodies 20 units. 
Table I. Clinical characteristics and laboratory findings from the time-point of renal biopsy.

\begin{tabular}{|c|c|c|c|c|c|c|c|c|c|c|c|c|c|}
\hline Patient & Age / sex / ethnicity & $\begin{array}{l}\text { Fulfilled } \\
\text { ACR criteria }\end{array}$ & $\begin{array}{l}\text { SLE prior } \\
\text { nephritis } \\
\text { (months) }\end{array}$ & APS & $\begin{array}{l}\text { Histo- } \\
\text { pathology } \\
\text { (ISN/RPS) }\end{array}$ & $\begin{array}{l}\text { Estimated } \\
\text { GFR } \mathrm{mL} / \mathrm{min} \\
\text { month } 0\end{array}$ & ANA titer & Anti-ENA & $\begin{array}{l}\text { Anti- } \\
\text { dsDNA } \\
\text { titer }\end{array}$ & $\begin{array}{l}\text { C1q } \\
(\%)^{*}\end{array}$ & $\begin{array}{l}\text { Anti-C1q } \\
\text { (units/L) }\end{array}$ & $\begin{array}{l}\text { CRP } \\
\text { (mg/L) }\end{array}$ & $\begin{array}{l}\text { Anti-CRP } \\
\text { (units/L) }\end{array}$ \\
\hline A & 35 / F / Caucasian & $1,3,6,7,9,10,11$ & 60 & yes & IV-G (A/C) & 68 & $\geq 3200 \mathrm{H}+\mathrm{ND}$ & SS-A/SS-B & $\geq 160$ & 59 & 110 & 2.3 & 14 \\
\hline B & 24 / F / Caucasian & $1,5,6,7,9,10,11$ & 14 & no & IV-G (A) & 89 & $\geq 3200 \mathrm{H}$ & SS-A/SS-B/Sm & $\geq 160$ & 53 & 440 & 16.1 & 13 \\
\hline C & 27 / F / Caucasian & $1,5,7,10,11$ & 12 & no & IV-G (A/C) & 55 & $\geq 3200 \mathrm{H}$ & negative & $\geq 160$ & 67 & negative & 2.4 & negative \\
\hline $\mathrm{D}$ & 69 / M / Caucasian & $3,5,7,10,11$ & 0 & no & IV-G (A/C) & 25 & $800 \mathrm{H}$ & negative & negative & 96 & 27 & 13.9 & 32 \\
\hline $\mathrm{E}$ & 41 / F / Asian & $4,5,6,7,9,10,11$ & 0.5 & no & IV-G (A) & 100 & $\geq 3200 \mathrm{H}+\mathrm{S}$ & SS-A/SS-B/Sm/snRNP & $\geq 160$ & $<6$ & 63 & 3.0 & 14 \\
\hline
\end{tabular}

\begin{tabular}{|c|c|c|c|c|c|c|c|c|}
\hline Patient & $\begin{array}{l}\text { R-SLEDAI } \\
\text { month } 0\end{array}$ & $\begin{array}{l}\text { SDI } \\
\text { month } 0\end{array}$ & $\begin{array}{l}\text { Prednisolone } \\
\text { (mg/day) }\end{array}$ & $\begin{array}{l}\text { Induction } \\
\text { therapy }\end{array}$ & $\begin{array}{l}\text { R-SLEDAI } \\
\text { month } 6\end{array}$ & $\begin{array}{l}\text { Renal } \\
\text { responder }\end{array}$ & $\begin{array}{l}\text { Estimated GFR } \mathrm{mL} / \mathrm{min} \\
\text { follow-up } \geq 3 \text { years }\end{array}$ & Follow-up $\geq 3$ years \\
\hline A & 12 & 0 & 0 & Cy, Am & 12 & no & 49 & Persistent proteinuria \\
\hline B & 12 & 3 & 20 & Cy, Am & 0 & yes & 96 & Re-biopsy at 6 month showed ISN/RPS II \\
\hline C & 12 & 0 & 40 & Cy, Am & 0 & yes & 80 & Renal remission \\
\hline $\mathrm{D}$ & 8 & 0 & 15 & Cy & 8 & no & 23 & Minimal proteinuria \\
\hline E & 8 & 0 & 40 & Cy, Am & 0 & yes & 89 & Renal remission \\
\hline
\end{tabular}

* C1q analyzed by electroimmunoassay with reference $78-131 \%$ based on healthy blood donors.

F, female; M, male; ACR, American College of Rheumatology; APS, anti-phospholipid syndrome; ISN/RPS, International Society of Nephrology/Renal Pathology Society; GFR, glomerular filtration rate; H, homogenous; ND, nuclear dots; S, speckled; ENA, extractable nuclear antigens; C1q, complement protein 1q; CRP, C-reactive protein; R-SLEDAI, renal SLE disease activity index; SDI, Systemic Lupus International Collaborating Clinics/ACR damage index; SS-A, Sjögren syndrome A antibody; SS-B, Sjögren syndrome B antibody; Sm, Smith; snRNP, small nuclear ribonucleoprotein; Cy, cyclophosphamide; Am, antimalarials 
Table II. Primary detection antibodies and secondary gold-labeled antibodies (gold-conjugate size indicated) used for immunogold electron microscopy stainings.

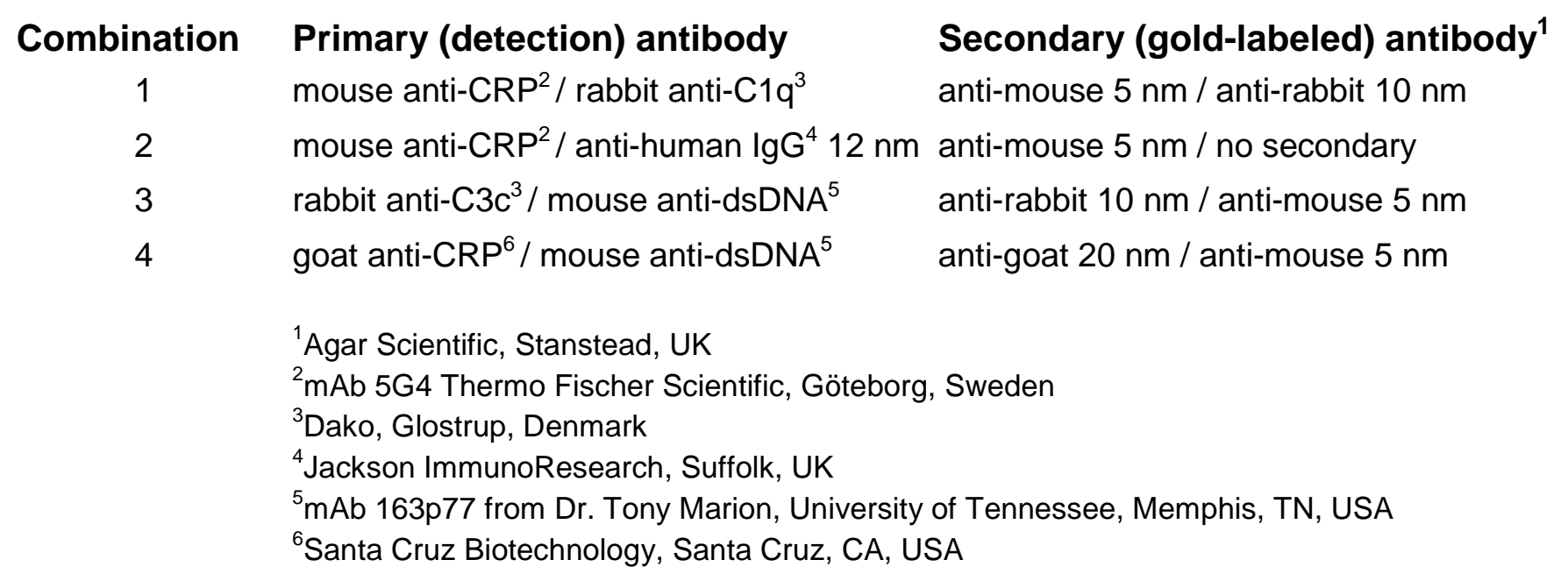

